\title{
Technology and Future Prospects for Lightweight Plastic Vehicle Structures
}

by F. Stodolsky, R.M. Cuenca, and P.V. Bonsignore

Center for Transportation Research, Energy Systems Division,

Argonne National Laboratory, 9700 South Cass Avenue, Argonne, Illinois 60439

August 1997

Work sponsored by United States Department of Energy,

Assistant Secretary for Energy Efficiency and Renewable Energy,

Office of Transportation Materials 
This report is printed on recycled paper. 


\section{DISCLAIMER}

This report was prepared as an account of work sponsored by an agency of the United States Government. Neither the United States Government nor any agency thereof, nor any of their employees, make any warranty, express or implied, or assumes any legal liability or responsibility for the accuracy, completeness, or usefulness of any information, apparatus, product, or process disclosed, or represents that its use would not infringe privately owned rights. Reference herein to any specific commercial product, process, or service by trade name, trademark, manufacturer, or otherwise does not necessarily constitute or imply its endorsement, recommendation, or favoring by the United States Government or any agency thereof. The views and opinions of authors expresced herein do not necersarily state or reflect those of the United States Government or any agency thereor. 


\section{DISCLAIMER}

Portions of this document may be illegible electronic image products. Images are produced from the best available original document. 


\section{Preface}

Most information for this report was obtained in 1994, and early drafts of this report were completed in 1995. While significant advances have been reported in the field of automotive plastics over the past three years, the authors feel their conclusions are still valid. 


\section{Contents}

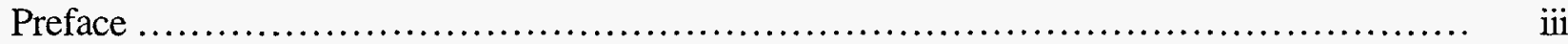

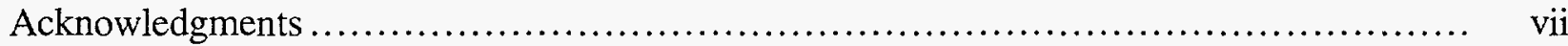

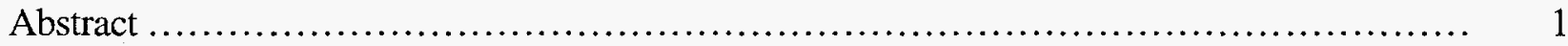

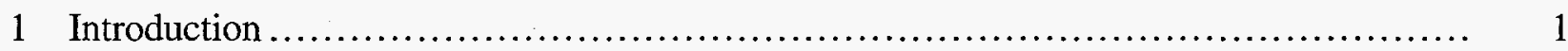

2 Mass Reduction Potential of Polymer Matrix Composites ............................. 3

2.1 Property Considerations of Component Materials .............................. 3

2.2 Potential of Polymer Matrix Composites for Vehicle Mass Reduction................ 4

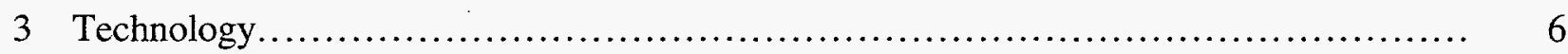

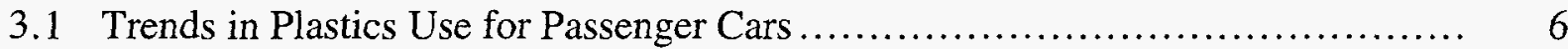

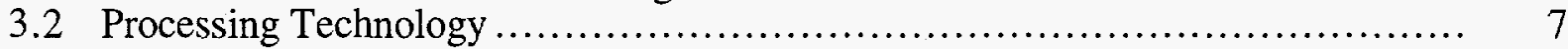

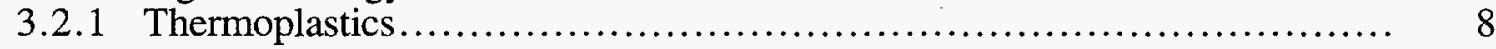

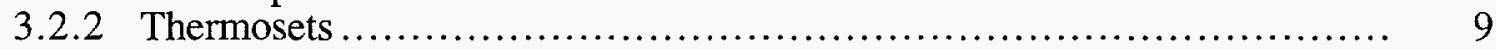

3.2.3 Composite Formulations......................................... 9

4 Carbon-Fiber Polymer Matrix Composite Vehicles ................................ 13

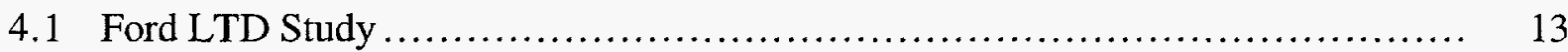

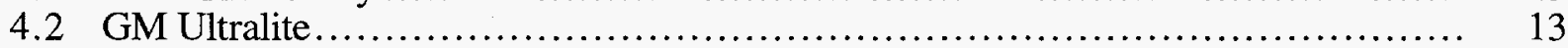

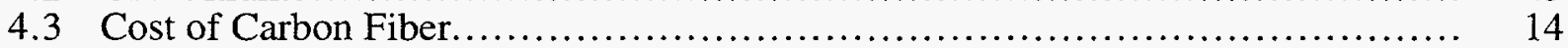

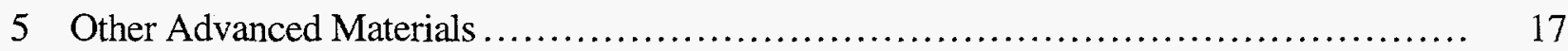

5.1 Thermoplastic Resin Composites ........................................ 17

5.1.1 Short-Fiber Composites for Near-Term Nonstructural Applications......... 17

5.1.2 Continuous-Fiber Composites for Structural Applications ................... 19

5.2 Liquid Thermoplastic Composites............................................. 21

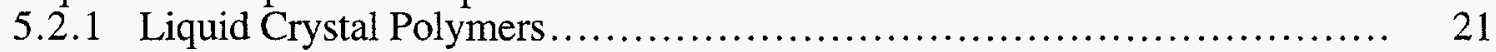

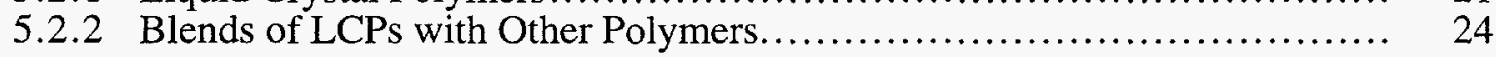

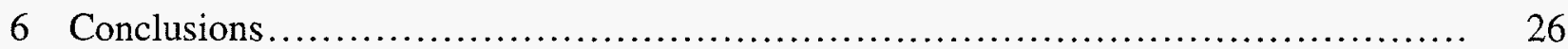

7 References............................................................... 27

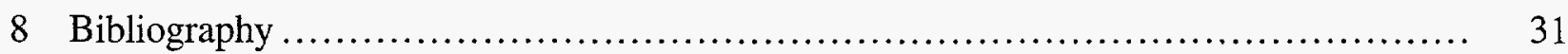

\section{Tables}

1 Weight Reduction Potential of Automotive Material Systems........................ 5

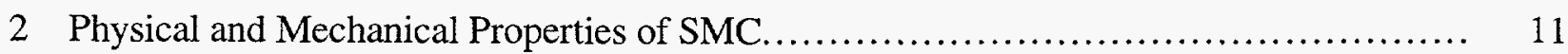




\section{Tables (Cont.)}

3 Comparison of General Characteristics of Thermoset and Thermoplastic Matrixes....... 18

4 Material Property Comparison for Thermoplastic Fiber Composites ................. 20

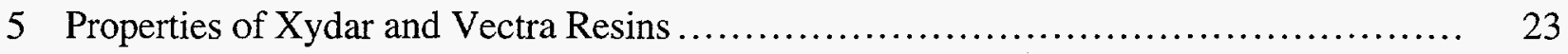

Figures

1 Densities and Elastic Moduli of Various Materials Relative to Steel..................... 3

2 Plastic Use in Light-Duty Vehicles......................................... 6

3 Plastic Use as a Percentage of Light-Duty-Vehicle Weight.......................... 7

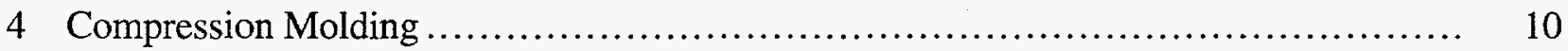

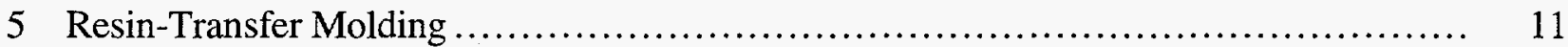

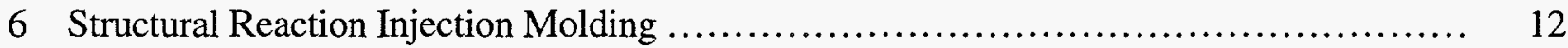




\section{Acknowledgments}

The authors thank Dr. James J. Eberhardt and Dr. Sidney Diamond of the Office of Heavy Vehicle Technologies (formerly the Office of Transportation Materials), U.S. Department of Energy, for their help, continuous support, and valuable guidance. The authors also thank Dr. Danilo Santini of ANL and the external reviewers for their thorough technical review and helpful suggestions. We also thank Ellen Hathaway, our technical editor; the Argonne Graphics Department for the illustrations; and Argonne Document Processing and Control for word processing of this report. 


\title{
Technology and Future Prospects for Lightweight Plastic Vehicle Structures
}

by

\author{
F. Stodolsky, R.M. Cuenca, and P.V. Bonsignore
}

\begin{abstract}
The state of the technology and the materials and processing issues of using plastics in vehicle body applications (structural and semistructural) were assessed. Plastics are significantly lighter in weight, more easily fabricated into complex shapes, and more corrosion resistant than sheet steel, high-strength steel, or aluminum. However, at their current stage of development, plastics are deficient in one or more necessary properties: heat resistance and dimensional stability, stiffness and tensile strength, toughness, and impact resistance. To upgrade their physical properties for automotive chassis/body applications, plastics need to be compounded with suitable reinforcing fibers. As a short-term approach, the material of choice is a composite structure made with low-cost glass-fiber reinforcement, such as that made in the resin-transfer-molding (RTM) process and used in the body of the Dodge Viper. However, RTM technology based on thermosets requires a processing cycle time that is too long for large production runs. Adaptation of RTM to the formation of thermoplastic composite bodies could have a significant advantage over thermoset technology. Cyclic oligomers, which are precursors to thermoplastic matrix polymers, show promise for this application. Farther on the horizon are advanced composites compounded with the much more expensive (but stronger and stiffer) carbon-fiber reinforcement. However, significant price reductions of precursor materials and advances in processing and fabrication would be needed. Other materials holding promise are liquid crystal polymers (LCP) and LCP blends with other polymers (molecular composites). However, the cost of monomers and the subsequent polymerization technology also remains a considerable drawback to the widespread and increasing acceptance of LCPs.
\end{abstract}

\section{Introduction}

Automakers are constantly working on new design concepts and materials to reduce vehicle weight. They are motivated by potential cost reductions, the corporate average fuel economy (CAFE) standards, and electric vehicle mandates. In spite of advances by the automakers in achieving weight reductions, mainly by using plastics and integrating parts, fleet CAFE levels have not increased, because consumers, reacting to low fuel prices relative to the overall cost of vehicle ownership, have opted for larger, more option-laden vehicles. 
If CAFE standards are raised, or if oil prices rise sharply over an extended period of time, automakers will need to further reduce vehicle weight. Downsizing is one option. However, automakers are keenly interested in cost-effective, lightweight materials that can reduce vehicle weight without sacrificing vehicle utility. In addition, the zero-emission vehicle requirements will encourage automakers to produce lightweight vehicle structures to improve the range of electric vehicles.

In this report we focus on the use of polymeric materials in passenger cars. Other lightweight materials, including aluminum and magnesium, are under development by automakers and suppliers; for these materials the weight reduction potential is well-documented. However, we found that there are misconceptions about the weight reduction potential and fabrication technologies for polymeric materials.

While growth in the use of polymeric materials in passenger cars has been impressive, analysis reveals that very little of this growth has been in structural functions. Plastics have come to dominate the interior-component application area, and they have experienced rapid growth in the exterior trim category as well. Their use as energy-absorbing instrument-panel pads can be considered at least partially "structural" in nature, and as bumper systems, even more so. But even in these two applications, the main property responsible for the selection of polymeric material systems is their specific energy absorption, especially when combined with a welcome amount of "give," as is characteristic of urethane foam and similar systems.

Polymer composite bumper beams (replacing aluminum and/or steel) can be considered true structural members. Their use in passenger cars, although still rather modest, is expected to increase in the future. But overall, the use of polymers in automotive components having a significant structural function, like bumper beams or composite suspension springs, is still rare. Even the exterior body panels used in such plastics-intensive vehicles as the Corvette, Viper, Fiero, Saturn, Lumina van, and Camaro/Firebird are essentially unloaded, with steel internal-space frame-structures taking all the load.

In this report, we begin with a discussion of the reasons for the lack of structural applications within the polymeric material family and discuss the mass reduction potential of polymer matrix composites (PMCs) (Section 2). Next, we discuss technology, including trends in PMC use for passenger cars, and processing technology (Section 3). In Section 4, we discuss case studies of carbon-fiber PMC vehicles and the cost of carbon fiber. Other advanced materials, such as liquid crystal polymers (LCPs), are discussed in Section 5. Finally, in Section 6, we suggest research to improve the performance of polymeric materials for lightweight vehicle-body structures. 


\section{Mass Reduction Potential of Polymer Matrix Composites}

\subsection{Property Considerations of Component Materials}

There are two ways to replace a given component with a lighter weight equivalent: switch to a material with much lower density or switch to one with far higher strength or rigidity. The key performance parameter for body structures is specific strength or rigidity, i.e., strength or rigidity per unit volume or unit mass. Energy absorption and denting are two other important commonly used criteria. Figure 1 compares the elastic modulus (one characteristic that correlates with rigidity) and the density of various materials relative to steel.

Ferrous materials are characterized by high strength and rigidity but also by high density. The lightest metals (aluminum and magnesium) are characterized by medium strength and rigidity but low density. The relative specific (RS) properties show the effect of the combination of these properties more clearly. High-strength, low-alloy (HSLA) steel, for instance, shows higher specific strength than mild steel, as would be expected, because both have the same density; however, by definition, HSLA steel has higher tensile strength. Because both HSLA and mild steel have the same value for elastic modulus, as well as for density, their values for RS-elasticity are equal. The RS-strength of the light metals is superior to that of the ferrous metals, primarily because of the low density of the light metals. On the other hand, RS-elasticity of the light metals is about the same as that of the ferrous metals, because the rather low elastic modulus of the light metals offsets most of the advantages of low density. This fact partially explains why aluminum performs better, on a weight basis, when it replaces steel in applications where strength is the main design criterion, as compared to applications where rigidity is the main design criterion (e.g., engine cylinder heads vs. body panels).

The reasons for the lack of structural applications by the polymeric material family and even by the most common composites, such as sheet molding compounds (SMCs), or glass-reinforced

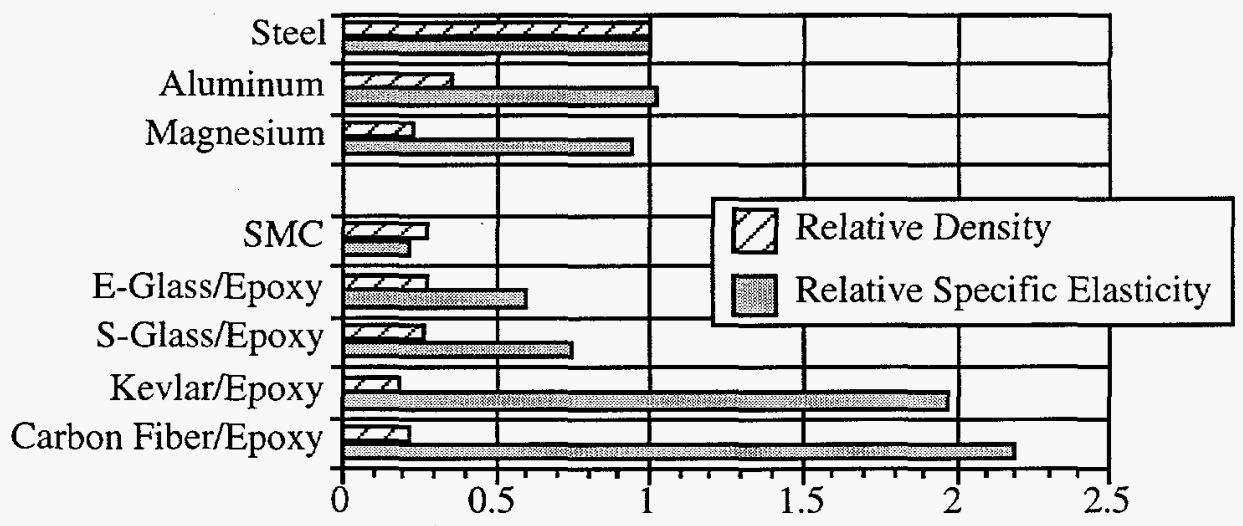

FIGURE 1 Densities and Elastic Moduli of Various Materials Relative to Steel 
esters, can be traced to the low strength and rigidity of these materials relative to iron and steel. Most polymeric materials (the exception being the high-performance composites) lack the specific strength and rigidity to replace steel or iron in structurally demanding applications. Polymer-based composites are characterized by very low densities, outstanding strength (in the direction of the fibers), and rather low rigidity. Unreinforced (or low-reinforcement) polymers also are lowdensity, but they have much lower strength and rigidity than composites. Composites, especially the higher performance types (carbon, graphite, and Kevlar), have outstanding RS-strength (unidirectional), while RS-rigidity is merely good. Polymers and low-performance composites have good RS-strength but rather poor RS-rigidity. Consequently, structural composites are often used in conjunction with foam cores (to improve rigidity through larger cross-sections), and highperformance composites are necessary on structures where rigidity is important.

\subsection{Potential of Polymer Matrix Composites for Vehicle Mass Reduction}

We have searched the literature for the best applications of composites in passenger cars and related vehicles and have found very little to support the claim that use of anything other than a high-performance composite will result in a significant reduction of mass. Most of the examples found in the literature where a fiberglass-based composite was used to replace a steel structural (body) member show that the mass saving, if any, is marginal. Weight reduction achieved by using glass fibers in structural members is typically on the order of 25-35\% (Winter 1994) much less than the $47 \%$ weight savings now achieved with aluminum (Sherman 1995). The main reason why a fiberglass-based composite is not effective in achieving significant mass reduction is that the main design criterion for most body parts is rigidity (rather than strength), and the elastic modulus for fiberglass-based composites is not very high. The relative mass of different structures, as well as an estimate of the effect on total vehicle mass, is shown in Table 1.

The usual manufacturing approach for advanced PMC products is the extremely laborintensive manual lay-up process. ${ }^{1}$ This process involves direct placement (by hand) of precut pieces of prepreg (pre-impregnated tape - long strands of fibers or weaves impregnated with epoxy resin) in a mold, which is placed in an autoclave for curing. This manufacturing process is not only inherently slow and labor-intensive, but it also tends to generate a significant amount of scrap (approaching 50\% in the case of complex parts), making the high material-cost problem even worse. The rigidity of the parts is a strong function of the fiber content of the composite, which must be kept around the $60 \%$ level in order to obtain relatively high moduli. It is extremely difficult in such popular processes as resin transfer molding (RTM) to achieve anywhere near 60\% fiberreinforcement content. Given these problems, it is not surprising that the average cost of advanced PMC components for the aerospace industry (the single largest market for these materials)

1 In the IBIS Associates study, a simulation of the manufacturing costs associated with the manual lay-up process at very low production rates $(5,000$ units per year), indicated that the process was about $50 \%$ more expensive than conventional, high-volume, steel-body production (Dieffenbach 1992). 
TABLE 1 Weight Reduction Potential of Automotive Material Systems

\begin{tabular}{lc}
\hline \multicolumn{1}{c}{$\begin{array}{c}\text { Body Structure } \\
\text { Material Systems }\end{array}$} & $\begin{array}{c}\text { Relative Mass, Body } \\
\text { Structure/Total } \\
\text { Vehicle }\end{array}$ \\
\hline All steel & $100 / 100$ \\
Glass-fiber composite/steel & $73 / 92$ \\
Aluminum/steel & $65 / 90$ \\
All aluminum & $53 / 87$ \\
Carbon-fiber composite/steel & $55 / 87$ \\
Carbon fiber composite monocoque & $48 / 67$ \\
\hline
\end{tabular}

a Assumes body structure is about $28 \%$ of total vehicle mass, and other components are not downsized to compensate for body mass reduction. If chassis and other components are downsized, an additional $7-9 \%$ mass reduction is possible without using lighter materials in these components.

Sources: Adapted from Sherman (1995); U.S. Congress (1988); and Chang (1981).

is about $\$ 150 / \mathrm{lb}$ (Robinson 1991). Special advanced PMC-based components for racing cars are regularly sold at prices ranging from $\$ 108$ to $\$ 400 / \mathrm{lb}$ (Applied Racing Technologies Group 1993).

Given these process limitations and high material costs, the automotive industry has been reluctant to adopt advanced PMC-based components for any of their volume vehicles. In 1979, at the height of the oil crisis, Ford considered using an air-conditioner compressor mounting bracket made with graphite-fiber composite. Even though using the composite part would have saved roughly $5 \mathrm{lb}$ over the standard cast-iron bracket (about a $71 \%$ mass reduction), the premium of almost $\$ 10$ per unit proved to be too much.

As of 1994, only two high-performance PMC-based components were in volume use: a leaf-type, rear-axle suspension spring used in the Corvette and Camaro/Firebird sports cars and a graphite-reinforced driveshaft used in some GM light trucks. The $10 \mathrm{lb}$-leaf spring, made from fiberglass/epoxy composite material, replaced a multileaf steel spring that weighed $41 \mathrm{lb}$. The composite driveshaft replaced a two-piece steel shaft and offered significant mass and complexity reduction. The main property allowing this substitution is stiffness (to avoid vibrations), but this successful application has received a great deal of competition from another lower cost composite, aluminum-ceramic, and may be replaced. In racing car applications, where money is often no object, advanced PMC components are used regularly. The high rigidity and low mass of bodies made from advanced PMCs result in handling improvements that are considered well worth the premium. 


\section{Technology}

\subsection{Trends in Plastics Use for Passenger Cars}

Historical and projected use of plastics in passenger cars are shown in Figures 2 and 3 (Ward's Automotive Yearbook various years; AAMA various years; University of Michigan 1994). In 1973, plastic usage amounted to about $140 \mathrm{lb}$ for a 4,014-lb mid-size vehicle, or about $3.5 \%$ of the vehicle weight. In 1991, plastic usage grew to about $234 \mathrm{lb}$ for a 3,123-lb mid-size vehicle, or about $7.5 \%$ of the vehicle weight. Projected plastic use is expected to reach $300 \mathrm{lb}$ for a 2,811-lb mid-size vehicle in 2003 if CAFE reaches $35 \mathrm{mpg}$, according to a University of Michigan survey (University of Michigan 1994). From these figures, we see that while plastic use has increased substantially over the past 20 years, vehicle weights have dropped substantially more than the weight reduction by the substitution of metals with plastic. More significant weight reductions occurred through improved designs (such as cab-forward design) and structures (such as the unibody structure where the chassis and body are integrated into one structure). Still, polymer matrix composites are used infrequently in modern passenger cars.

What are future prospects for plastics in passenger cars? The trend is not leading toward any particular significant breakthrough, such as the use of high-performance composites or possible widespread substitution of composites for steel in structural body application or the replacement of cast iron in engines. Rather, the trend in the foreseeable future is one of replacing

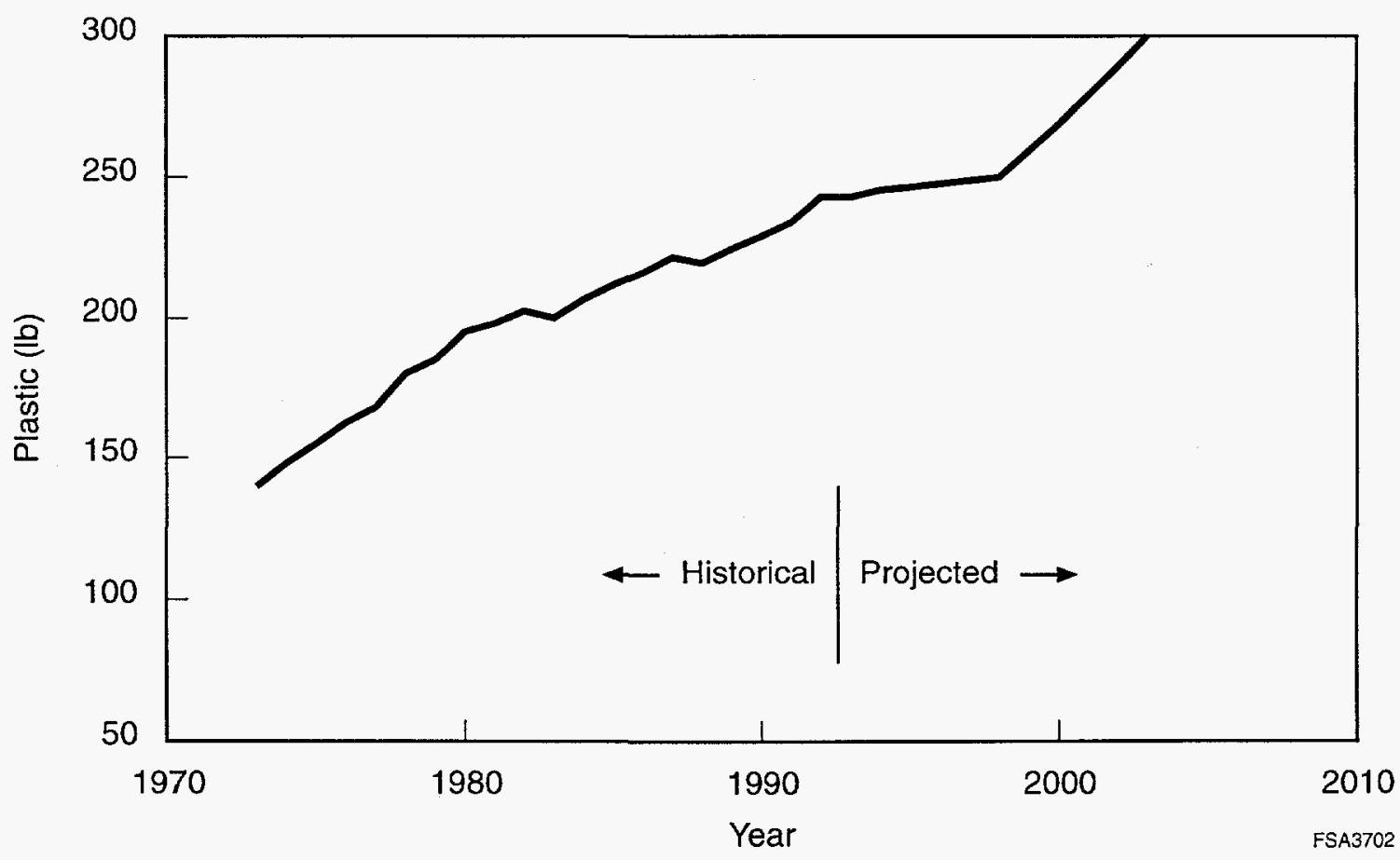

FIGURE 2 Plastic Use in Light-Duty Vehicles 


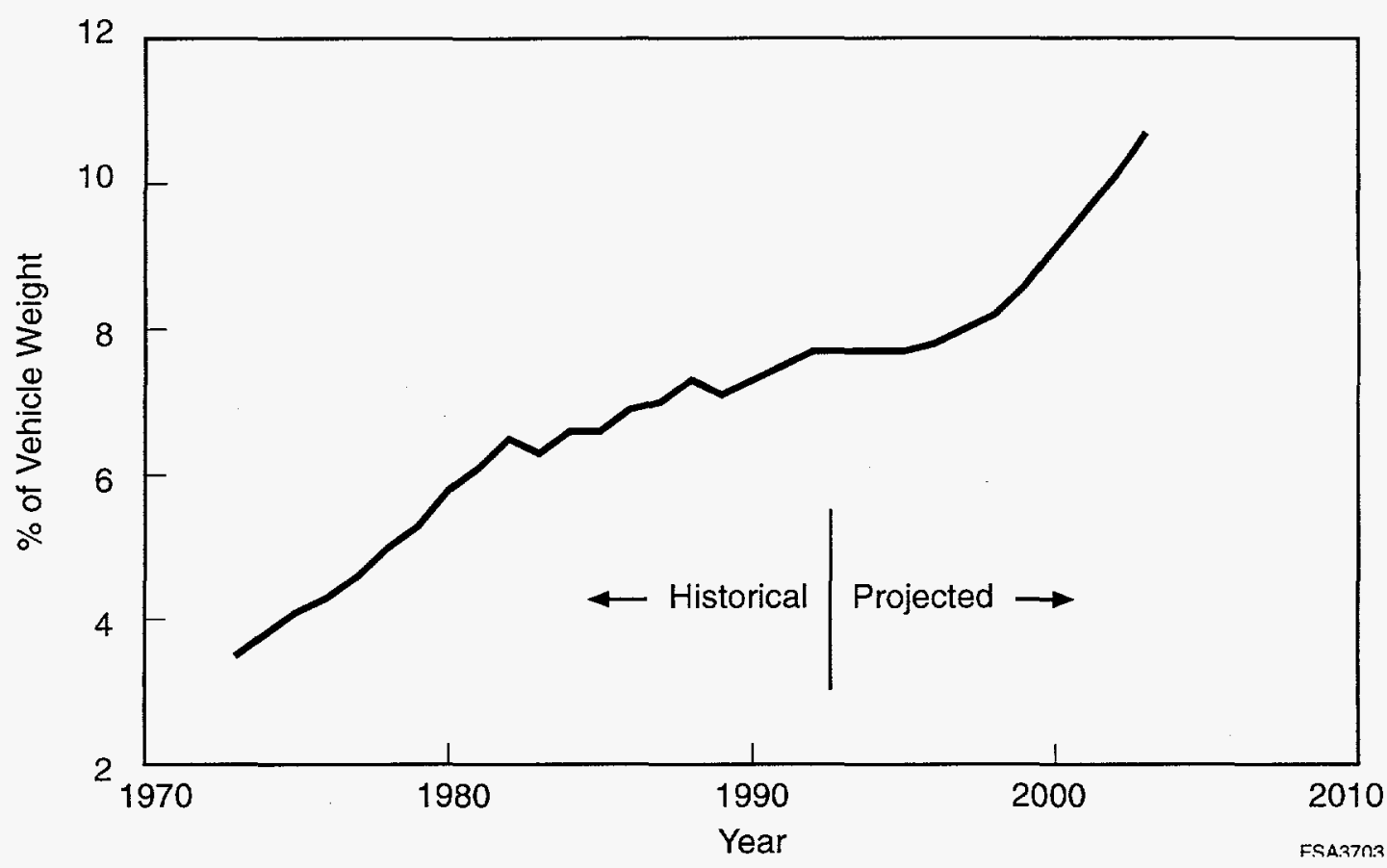

FIGURE 3 Plastic Use as a Percentage of Light-Duty-Vehicle Weight

steel or aluminum components in those applications where the substitution leads to a lower cost product, whether by parts consolidation or through a more effective process. In addition to the very successful bumper applications, which likely will become completely polymer material systems, possible future applications include fenders (lower weight, superior denting resistance), rear decklids and/or hoods, and perhaps even doors. Unless significant breakthroughs in material properties and processing costs are achieved, applications of composites for exterior body panels are not expected to grow, and may even decline; such applications may be restricted to low-volume specialty vehicles, like the Viper and Corvette. Under-the-hood applications, however, are still growing, with intake manifolds and valve covers being two new areas for molded composites.

\subsection{Processing Technology}

In this section, we discuss the production of polymers used as the binder materials (matrices), the production of fiber reinforcements, and the production of parts from PMCs. There are two broad categories of polymers - thermoplastics and thermosets. As defined in HighPerformance Composites Sourcebook '96, "thermoplastics are formed by heat and cooling and can be reshaped more than once" (1995). Thermosets are "cured by heat and pressure or with a catalyst into an infusible and insoluble material. Once cured, a thermoset cannot be returned to the uncured state."2

2 A recent study indicates that it may be possible to thermally reverse urethane-based crosslink bonds, so reforming of polyurethane thermosets might be possible (Bigg and Markle 1996). 
The annual production of polymers is in the range of $70-80$ billion pounds per year; the estimate for 1996 was 76 billion pounds (SPI 1997). The largest proportion of polymers, perhaps more than 95\%, are produced from petrochemical feedstocks. The main building blocks (monomers and monomer precursors) for both thermoplastics and thermosets are relatively few in number, consisting of such simple olefins as ethylene, propylene, and isobutylene and such aromatic compounds as benzene, toluene, and xylene. Both olefinic and aromatic compounds are now mainly produced by the reforming of petroleum feedstocks (Dale 1980). Despite the perceived magnitude of polymer production, only about $3-4 \%$ of petroleum consumption goes into the production of polymers (Dale 1980). The following sections discuss the downstream processing of thermoplastic- and thermoset-based PMCs.

\subsubsection{Thermoplastics}

Approximately $90 \%$ of the polymers produced each year are thermoplastics (SPI 1997). The largest components of the thermoplastics produced are the polyolefins, consisting of polypropylene (PP) and polyethylene (PE) (which is further subdivided into low density polyethylene [LDPE], linear low-density polyethylene [LLDPE], and high-density polyethylene [HDPE]). Other large-volume thermoplastics include polyvinyl chloride (PVC), polystyrene (PS), and acrylonitrile-butadiene-styrene (ABS) copolymers. Thermoplastics produced in lesser quantity (but still important) include polyethylene terephthalate (PET) (soda pop bottles), polyamides (nylons), and polyoxymethylene (Delrin and Celcon) (SPI 1992).

As supplied, thermoplastics are already in their final high-molecular-weight stage, being composed of separate, independent, and mostly linear polymer chains. Fabrication into useful forms and shapes involves first using heat and pressure to melt and separate these polymer chains, and then redirecting their molten shape by melt extrusion, injection molding, vacuum forming, or compression molding into the shape of the desired final product.

Extrusion of molten polymer through shaped and heated die lips, followed by cooling, leads to continuous lengths of profiles, sheets, films, and fibers (Kruder 1990). Injection molding involves the injection of the molten polymer into mold cavities to form complex monolithic-shaped forms in a batch process (Rubin 1990). Compression molding generally involves subjecting a reinforced preform mat (saturated with the thermoplastic resin) to heat and pressure in a flat or moderately curved two-piece mold of high-quality surface finish, followed by cooling to set the final shape (Hull 1990).

A prime consideration with thermoplastics is that they can be readily reshaped by the reapplication of heat and pressure into new forms and shapes, which means that thermoplastics are good candidates for reclamation and recycling after their original function has ended. However, thermoplastics (without strengthening fibers) cannot be used for structural applications. Weight savings potential for these compounds are relatively small. 


\subsubsection{Thermosets}

In contrast to thermoplastics, thermosets are in a low-molecular-weight uncured stage and are generally supplied as viscous liquids or pseudoplastic solids. A significantly large class of thermosets is glass-fiber-reinforced polyesters (GRPs), including SMCs and bulk molding compounds (BMC). GRPs are a complex mixture of low-molecular-weight reactive polyesters dissolved in liquid styrene monomer and heavily extended with glass fibers, mineral fillers, catalysts, and thickening agents (Mao 1990). Fabrication involves the application of heat and pressure, which causes chemical curing involving polymerization of the total mass into its final cured shape. Short-fiber-reinforced thermoset-based composites are generally used for semistructural applications. More advanced, continuous-fiber thermoset-based composites are generally used for structural applications.

In sharp distinction to thermoplastics, the final cured mass is composed of a completely interlocked, cross-linked network of polymer chains. Since reapplication of heat and pressure can not reverse the curing process, no reshaping or reforming of thermosets is possible. ${ }^{3}$ Therefore, cost-effective reclamation and recycling of discarded thermosets, at the present level of technology, seem remote. For automotive applications using a low volume of composites (e.g., the Dodge Viper at approximately 5,000 units/yr), the lack of recyclability of thermoset polyester resin does not seem to be a severe constraint. For large-volume thermoset products, such as the $>200,000$ unit volume for the hoods of the Ford Econoline vans, the lack of meaningful recyclability could be a significant drawback. In this regard, thermoplastic composites could have a much higher level of political acceptability.

In addition to the large-volume GRPs, thermosets include epoxy resins (such as those used in advanced composites for high-performance aircraft), phenolics (high-temperature and arc-resistant electrical components), polyurethane foams (rigid and flexible), and polyurethane and polyurea polymers, such as those used for structural reaction injection molding (SRIM) and reinforced reaction injection molding (RRIM) (SPI 1992).

\subsubsection{Composite Formulations}

All plastic composites are composed of two basic components: (1) the continuous polymer matrix, most usually thermoset in nature, and (2) the discontinuous fibrous reinforcement, usually glass fiber. For specialty composites, the reinforcement may be carbon fibers or microfiber minerals (such as potassium titanate or wollastonite).

3 Some recent advances in thermoset polyurethane-coating chemistry point to the possibility of thermally reversing urethane-based crosslink bonds, so that a degree of reforming of this specific type of thermoset plastic may be possible (Bigg and Markle 1996). 
For use in vehicle chassis/bodies, the favored composite is glass-fiber-reinforced thermoset polyester resin of either SMC or RTM, although SRIM based on thermoset polyurea-polyurethane technology is also being considered.

Sheet Molding Compound/Bulk Molding Compound. SMC is supplied as an uncured pseudoplastic solid in a sheet form that contains all the components needed to form the finished molded part. The SMC sheet consists of the unsaturated polyester resin dissolved in liquid styrene monomer and heavily loaded with filler (calcium carbonate, alumina trihydrate, talc, etc.). Chopped glass fiber, typically of short length (1-2 in.), is also included to a weight content of $40-45 \%$, as is a heat-activated polymerization catalyst (such as MEK peroxide). The whole mass is set into a pseudo-solid form by the addition of a thixotropic agent (such as magnesium oxide). The use of short fibers limits the use of SMC to nonstructural or semi-structural applications.

Heat and pressure (typically $110-160^{\circ} \mathrm{C}$ and $150-1,000 \mathrm{psi}$ ), applied to the SMC part in a large platen-press mold, activate the catalyst to initiate polymerization of the styrene monomer with the unsaturated polyester resin to give the final molded and cured thermoset part (Mao 1990) (see Figure 4). Typical physical and mechanical properties for cured SMC sheet are given in Table 2 (Mao 1990). Curing of the SMC parts in the heated mold typically requires a 2.5- to 4-min mold-residence time. The use of the molding press for flat sheet necessarily limits the complexity of the part to be molded. The design of the part must take into account the inelasticity of the glass fibers, so that deep-drawn areas do not become fiber "starved."

Resin-Transfer Molding. RTM results in finished formed parts similar in final composition to SMC. However, in contrast to the SMC system, glass-fiber reinforcement is preferably of a continuous nature in a preformed mat (preform). In fact, the preformed mat structure is required to prevent fiber displacement during the injection-filling step. In the processing, the glass-fiber reinforcement is placed in a two-piece matched cavity mold equipped with multiple entry ports and vent holes (see Figure 5). The two faces of the mold are then are closed and clamped. The liquid-catalyzed polyester resin formulation is injected into the mold cavity, and the mold is heated. The liquid polyester resin to be injected must be of sufficiently low viscosity that the catalyzed resin completely fills and permeates the glass preform before polymerization into the gel state becomes appreciable. Typically, the gel time is at least 1.5 times the fill time.

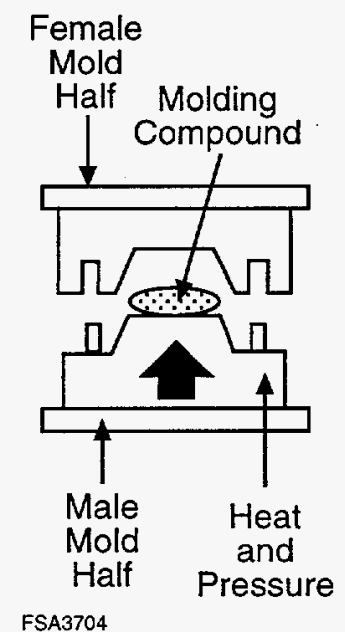

FIGURE 4 Compression Molding 
TABLE 2 Physical and Mechanical Properties of SMC

Properties

Specific gravity

Hardness, Barcol

Dielectric strength $(\mathrm{V} / \mathrm{mm})$

Tensile strength $(\mathrm{MPa})^{\mathrm{a}}$

Tensile modulus $(\mathrm{MPa})^{\mathrm{a}}$

Flexural strength (MPa) ${ }^{a}$

Flexural modulus $(\mathrm{MPa})^{\mathrm{a}}$

Compressive strength $(\mathrm{MPa})^{\mathrm{a}}$

Izod impact, notched $(\mathrm{J} / \mathrm{m})^{\mathrm{b}}$
Value

$1.6-2.6$

$50-70$

$9.7-12.7$

$55.16-172.37$

$9,653-17,237$

$68.95-248.22$

$6,895-15,169$

$103.42-206.85$

$373.6-1,174.3$

a To convert MPa to psi, multiply by 145 .

b To convert $\mathrm{J} / \mathrm{m}$ to $\mathrm{ft}-\mathrm{lbf} / \mathrm{in}$., divide by 53.38 .

Source: Mao (1990).

The low viscosity needed for a fast fill works against other needed attributes for the liquid resin, such as enough body to carry dispersed mineral fillers and coloring pigments. Some screening of fillers is inevitable, causing heterogeneity in part density and coloring. At one time, because the polymerizing polyester resin underwent significant shrinkage, part surfaces often showed fiber prominence and, hence, an acceptable automotive finish was not developed. In some cases, a separate gel coat without fiber reinforcement was polymerized onto the two faces of the mold; then the glass

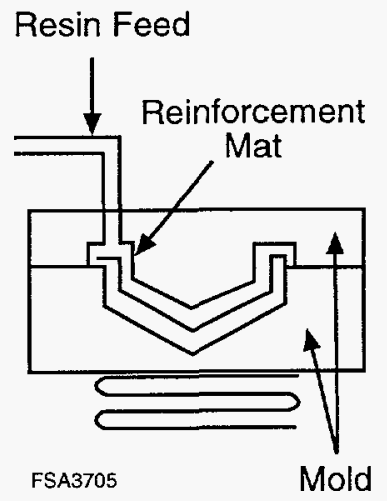

FIGURE 5 Resin-

Transfer Molding resin technology development, specifically new low-shrinkage resins, has obviated the need for the gel-coat approach to realize an acceptable surface.

Annual production volumes for RTM are significantly lower than those for SMC, in the range of 2,000 to 5,000 units (Hull 1990). This technology is limited to relatively low-production vehicles because of the relatively long time required for RTM compared to metal sheet stamping processes. 
RTM was chosen as the primary fabrication process for the body panels for the Dodge Viper because of low tool costs and process improvements that cut cycle times and improved surface finish. The gauge of the body panels is 0.100 in., reflecting a general industry push away from a previous norm of 0.135 in. The primary factor in the reduction was high-quality thermoformable glass mat preforms (from Vetrotex CertainTeed) and the low viscosity of the resin (from ICI Acrylics). Total glass content is $28-38 \%$. In the Viper application, considerably less filler is being used than is normal for a typical automotive surface.

For the Viper, a gel coat is being applied to the inner surfaces of the RTM mold. Before the gel coat is completely set, the thermoformable mat preforms are draped in the mold, and the molds are closed and clamped. Injection and curing of the catalyzed polyester resin completes the operation. Chrysler expects to eliminate the use of a gel coat as production advances by the adoption of low-shrinkage resins. Molder Aero Manufacturing reports cycle times ranging from $6 \mathrm{~min}$ to 10-15 min, depending on part size and shape. After demolding, the surface of the part is lightly sand-blasted to improve the adhesion of the final low-bake, two-part urethane paint system.

Structural Reaction Injection Molding. SRIM (also called Reinforced Reaction Injection Molding) very closely resembles RTM in processing features, with the exception that in place of a moderately viscous liquid-catalyzed styrene-polyester resin, the polymeric matrix is a thermoset polyurethane-polymeric system, resulting from the injection mixing of two very-low-viscosity monomeric reactants, a glycol, water, and a monomeric and/or polymeric di-isocyanate. As with RTM, SRIM processing requires liquid penetration of a glass-fiber-mat preform draped within a two-piece matched cavity mold (see Figure 6). In contrast to RTM, dispersed mineral fillers are not usually used. In contrast to the low pressure, $<100$ psi delivery pressures of the RTM polyester, SRIM technology requires high delivery pressure on the order of 3,000 psi because of the very high polymerization reactivity on mixing the two streams.

In comparison with other polymer process methods, SRIM offers several advantages that have sustained its growth. It is well-suited to the manufacture of large articles, which is impractical or uneconomical with conventional injection or compression processes. Startup time for SRIM is rapid, and tooling is relatively inexpensive. Tooling made from aluminum, which can be machined faster and is less expensive than the steel tooling used for injection molding, may be used for SRIM. For limited production runs and prototyping, using metal-filled epoxy or castable metal tooling can provide capital and item savings.

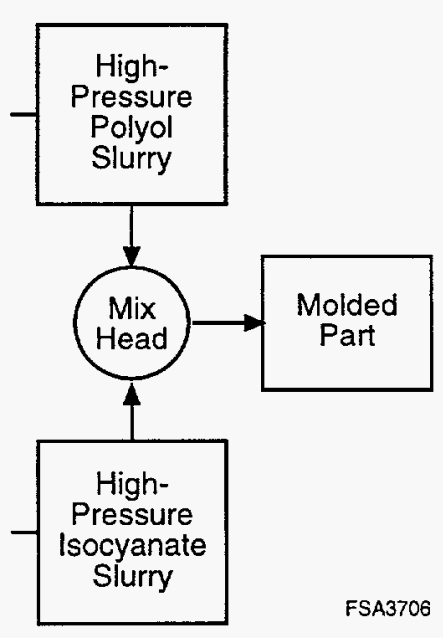

FIGURE 6 Structural Reaction Injection Molding 


\section{Carbon-Fiber Polymer Matrix Composite Vehicles}

In spite of the drawbacks, the industry has experimented with the use of advanced PMCs as substitute materials for automobile bodies, if only to determine the potential improvement in performance that they can offer in standard vehicles. ${ }^{4}$ All the examples we found that exhibit significant weight savings have made use of high-performance composites based on carbon (or in some cases, graphite) fibers and epoxy resin, and all substitutions have been made with aerospacestyle prepregs by a hand lay-up process. Two of the most interesting projects included a design study of a Ford LTD with a body made almost entirely of graphite-reinforced material (1988) (U.S. Congress 1988) and the more recent (1992) GM Ultralite concept car (Ashley 1992).

\subsection{Ford LTD Study}

The Ford LTD study, sponsored by OTA, involved Ford and Budd as contractor and subcontractor, respectively (U.S. Congress 1988). ${ }^{5}$ The basic approach was to replicate most of the metal parts in the body and chassis of a regular production automobile (a late 1970s Ford LTD, 4-door sedan) with graphite-reinforced composites. The powertrain was essentially standard, and a few suspension components remained in steel. Even though the basic design of the car was far from optimal for the use of advanced PMCs, the results were indeed remarkable. A total mass reduction of $33 \%$ was achieved, and the equivalent mass reduction for the body alone reached $52 \%$ (compared to $47 \%$ reduction with aluminum). The vehicle was not tested to determine safety or any performance parameters. This study was primarily an exercise to determine the effect of these types of materials on the manufacture of passenger cars.

\subsection{GM Ultralite}

The Ultralite concept vehicle was a study on high-fuel-economy passenger cars. The objective was to achieve record-setting mileage with a four-passenger sedan-type vehicle. The vehicle had a very-low-weight graphite-fiber-reinforced body with an extremely efficient aerodynamic shape $(\mathrm{Cd}=0.192)$ and a lightweight powertrain. For the sake of simplicity and mass reduction, the trunk, spare tire, power steering, brakes, and bumpers were eliminated, and the vehicle used a five-gallon fuel tank; aluminum-composite brake rotors; super-light, open-mesh seats (akin to lawn chairs); and high-pressure (65-psi), low-rolling resistance tires. The total mass of the vehicle was only $1,400 \mathrm{lb}$. With a 1.5 -liter, 111-hp, 2-stroke, aluminum engine, the vehicle

4 Carbon-fiber thermoset composites are used in some racing car bodies, certain exotic, high-priced performance vehicles, and in high-performance military applications. We limit our discussion to design studies for largevolume vehicle application.

5 This study used Ford's all-carbon-fiber PMC vehicle based on a 1979 Ford LTD. The design was not optimized as the vehicle had a separate body and ladder-type frame. Steel was replaced directly with carbon-fiber PMC in all chassis structural and most body components. 
achieved an acceleration of $0-60 \mathrm{mi} / \mathrm{h}$ in 7.8 seconds and fuel economy on the order of $100 \mathrm{mi} / \mathrm{gal}$ at a steady $50 \mathrm{mi} / \mathrm{h}$, or about $56 \mathrm{mi} / \mathrm{gal}$ on the EPA combined city/highway cycle.

The Ultralite monocoque integral body shell structure weighed $420 \mathrm{lb}$, about $30 \%$ less than a subcompact car (Escort) body-in-white. Much of the car's composite structure was made of layers of resin-impregnated carbon-fiber fabric plies bracketing a polyurethane foam core that was 1/8-1/4 in. thick. The layered parts were fabricated by Scaled Composites Inc. (Mojave, Calif.), by a manual lay-up process (Ashley 1992). First, the glass-fiber molds were coated with a releasing compound, which was followed by layers of carbon-fiber cloth. Epoxy resin was then applied, and the assembly was cured. In some cases, prepreg fabrics and honeycomb cores were employed. It is interesting and revealing that the Ultralite did not use any fiberglass in its construction. As lightweight automotive body structures go, the mass reduction appears good, but it is not particularly outstanding (47\% mass reduction in the body has already been shown by using aluminum substitution). Also, the high cost $(\$ 31 / \mathrm{lb})$ of the basic material (prepreg) used in the construction indicates the reality of advanced PMCs.

\subsection{Cost of Carbon Fiber}

The use of high-performance composites in passenger cars is severely restricted by two factors: the high cost of raw materials (reinforcing fibers, in particular) and the lack of an effective high-volume process. As previously shown in Table 1 and Figure 1, only the high-performance composites (those containing a greater proportion of such oriented, high-strength, reinforcing fibers as carbon, graphite, Kevlar, etc.) have adequate material properties to replace (and in fact, far outperform) steel in most structural applications. However, the cost of these high-performance materials is extremely high. In the following sections, material cost components are discussed in more detail.

Carbon Fiber Reinforcement. The ultimate reinforcing fiber in advanced composites for stiffness and strength is continuous carbon fiber. Unfortunately, making continuous carbon fiber from either polyacrylonitrile precursor fibers or petroleum-based mesophase pitch is a slow, energy-intensive process. Carbon fiber prices vary from under $\$ 10 / \mathrm{lb}$ to more than $\$ 1,000 / \mathrm{lb}$, with prices tending to increase sharply with increasing modulus. Prices also are dependent on the form in which the fiber is supplied, with the finest yarn being the most costly. The most commonly used types are such intermediate-modulus varieties as chopped fiber or tow containing 3,000 to 50,000 filaments. These usually are priced between $\$ 13$ and $\$ 30 / \mathrm{lb}$. A brief analysis of carbon fiber costs follows. A more comprehensive analysis of the relationships among fiber production processes, scalability, fiber quality and moduli, and costs is beyond the scope of this report.

There are two precursors of carbon fiber: pitch and polyacrylonitrile (PAN) (Lin 1992). Pitch is derived from either petroleum or coal tar. While pitch is intrinsically low in cost, its purification and manufacturing processes are not (Reinhart and Clements 1987). In addition, the strengths of pitch-based fibers are relatively poor compared to PAN-based fibers. 
Lowering the high cost of carbon fibers has been described as a "chicken or egg" problem. Increased demand will lower the price through economies of scale, but potential high-volume users are reluctant to commit to purchase the material unless costs are lowered significantly. A theoretical price of about $\$ 3 / \mathrm{lb}$ for large-scale production (70 times the present production of 15 million $\mathrm{lb} / \mathrm{yr}$ ) of PAN-based carbon fibers has been estimated by the industry (DeLong 1994). (Note that further processing of these fibers - weaving, pre-pregging, lay-up, and molding — would be required.) The $\$ 3 / \mathrm{lb}$ figure is derived by looking at the relationship between volume and cost for selected low-cost synthetic materials (such as nylon fiber), with adjustments for carbon fiber yield from PAN precursors (DeLong 1995).

However, the costs of carbon fiber production may not necessarily be scaleable like nylonfiber production processes. (Detailed calculations on scaleability are not available in the literature.) The PAN fibers must be stabilized at a temperature of $200-300^{\circ} \mathrm{C}$ in an oxygen-containing atmosphere while held under tension, adding to the processing cost (Schwartz 1984; Lin 1992). In the subsequent step of carbonization, the polymer enters a heated chamber (over $800^{\circ} \mathrm{C}$ ) containing an inert atmosphere and is converted into ribbons of continuous carbon hexagonal rings via pyrolysis (Lin 1992; Schwartz 1984). In this step, the PAN fibers are converted to carbon fibers at a yield of about 50\% (Schwartz 1984). The yield is inherently low because only the carbon from the PAN remains. Higher modulus graphite fibers can be produced from carbon fibers during the graphitization step that follows (temperatures above $2,500^{\circ} \mathrm{C}$ ).

Many critical factors affect carbon fiber properties. Crystalline size, crystal orientation, fiber porosity, and impurities are major factors (Lin 1992). Structural defects, both on the surface and in the interior of the fiber, greatly affect performance. Major processing parameters in the stabilization process are homogeneity (skin-core texture), extent of applied tension, and rate of stabilization. Major processing parameters in the carbonization process include rate of temperature rise, atmosphere of processing, and dust-free environment within the carbonization chamber. Without further study, it is unclear whether the carbon fiber process has the same cost-scaleability potential as the nylon-fiber process, which does not require multistep processing involving highly controlled, high-temperature, inert atmospheres. Further, even if these difficult technical problems are resolved, the buildup in production volume necessary to reach a cost of $\$ 3 / \mathrm{lb}$ would take a few decades.

It is interesting to note that GM has published a study on a technology to produce a less expensive carbon fiber that still has properties comparable with those of commercial fibers. GM's process involves growing carbon fibers from vapor-phase hydrocarbons onto catalytic metal particles (i.e., vapor-grown carbon fibers [VGCF]). According to GM projections, carbon fibers produced by this technology are expected to be intermediate in tensile strength and modulus but somewhat lower in cost than the traditional continuous carbon fibers (Tibbetts 1990).

Polymer Matrix. The preferred polymer matrix for advanced composites, such as that used in GM's Ultralite, is epoxy thermoset resins. Economies of scale are not expected to result in significant reductions in raw material costs, although epoxy resins, as a class, are not particularly expensive $(\$ 2-\$ 3 / \mathrm{lb})$. The expense is typically incurred in assembling the precursor prepreg tapes, 
which are composed of approximately 55\% carbon fiber and the deposited "tacky"-stage epoxy resin. These prepreg tapes are unstable and need to be refrigerated to prevent premature polymerization or curing. The price of prepreg tapes is in the range of $\$ 30-\$ 40 / 1 b$ (Slobodzinsky 1982).

Processing and Fabrication. To achieve satisfactory composite thickness, multiple layers of prepreg tapes are built up, taking full advantage of the unidirectional carbon-fiber orientation of each prepreg tape (Slobodzinsky 1982). The epoxy resin matrices are typically slow-curing resins. Data for prepreg tapes and fibers from Amoco Performance Products give gel times of 12-25 min at $180^{\circ} \mathrm{C}$, with a typical cure time of up to $2 \mathrm{~h}$ at $180^{\circ} \mathrm{C}$. Final cured composites sell for $\$ 100-\$ 400 / 1 b$ (Slobodzinsky 1982). 


\section{Other Advanced Materials}

While carbon-fiber PMCs have received much attention as a potential material for lightweight vehicles of the future, other advanced materials also show promise. Some of the more promising materials are discussed below.

\subsection{Thermoplastic Resin Composites}

Thermoplastic resins, some of which are classified as engineering resins, include some polyesters, polyamidimide, polyphenylene sulfide, polyether-etherketone (PEEK), and LCPs. They consist of long, discrete molecules that melt to a viscous liquid at the processing temperature, typically $260-371^{\circ} \mathrm{C}$; after forming, they are cooled to an amorphous, crystalline, or semicrystalline solid. The degree of crystallinity has a strong effect on the final matrix properties. Unlike the curing process of thermosetting resins, the processing of thermoplastics is reversible; by simply reheating the material to the process temperature, the resin can be formed into another shape, if desired. Thermoplastics, although generally inferior to thermosets in high-temperature strength and chemical stability, are more resistant to cracking and impact damage. However, recently developed high-performance thermoplastics (such as PEEK), which have semicrystalline microstructures, exhibit excellent high-temperature strength and solvent resistance. A simple comparison of the general characteristics of thermoset and thermoplastic matrices is provided in Table 3.

Thermoplastics offer great promise for the future from a manufacturing perspective, because it is easier and faster to heat and cool a material than it is to cure it. This characteristic makes thermoplastic matrices attractive to such high-volume industries as the automotive industry. Thermoplastics are used primarily with discontinuous fiber reinforcements (such as chopped glass or carbon/graphite filaments). However, there is a significant potential for high-performance thermoplastics reinforced with continuous fibers or, even more intriguing, for thermoplastic molecular composites in which the reinforcing components are LCP molecules.

\subsubsection{Short-Fiber Composites for Near-Term Nonstructural Applications}

PMCs based on short fibers show promise for weight savings on the order of $15 \%$ as compared to steel in such nonstructural or semistructural applications as exterior body panels. Short-fiber composites are not expected to replace body structural components. Structural steel is often needed to compensate for the low strength and rigidity of short-fiber composites. Therefore, developments in short-fiber composites are unlikely to lead to significant vehicle-body-weight savings. However, because of the significant level of industry activity in this technology, two approaches to exterior body panels based on thermoplastic resin binder matrices - injection molding and sheet molding - are discussed briefly below. Both approaches are being actively explored by DuPont. 
TABLE 3 Comparison of General Characteristics of Thermoset and Thermoplastic Matrixes

\begin{tabular}{lll}
\hline & \multicolumn{2}{c}{ Resin Type } \\
\cline { 2 - 3 } \multicolumn{1}{c}{ Characteristic } & Thermoset & Thermoplastic \\
& & \\
\hline & Low & High \\
Process temperature & High & Low \\
$\begin{array}{l}\text { Processing time } \\
\text { Use temperature }\end{array}$ & High & Low \\
Solvent resistance & High & Low \\
Toughness & Low & High \\
\hline
\end{tabular}

Source: D.R. Tenney, NASA Langley Research Center, as it appears in U.S. Congress (1988).

Injection Molding. DuPont has been actively promoting Bexloy K-550 as a thermoplastic injection-moldable composite material for potentially large-scale automotive body panel applications. Bexloy K-550, which is based on a modified PET polymer, was used for the injection-molded front fender of Chrysler's 1993 LH platforms. Advantages claimed for the Bexloy composite are dimensional stability (i.e., low coefficient of linear thermal expansion [CLTE]) and low sensitivity to hot humid conditions. Also claimed is resistance to the electrodeposition bake-coat temperature of $200^{\circ} \mathrm{C}$ in commercial assembly plants. Other advantages claimed are 30-40\% weight reduction versus comparable steel panels ${ }^{6}$ and increased design change flexibility because of the significantly lower cost of tooling at the generally lower production levels $(<100,000)$ being practiced in today's competitive metal market. Significant advantages claimed are inherent corrosion resistance and significantly improved "dent and ding" resistance versus comparable metal panels (Miller 1992).

Compression Molding. DuPont's "XTC" sheet product is a compression-moldable thermoplastic composite sheet based on a PET matrix. The XTC composite is electrocoat-oven capable and can be painted on existing steel-body paint lines.

A nonwoven product, XTC is made by the traditional papermaking process, and consists of 25-40\% long-strand fiberglass intermingled with stabilized PET fibers. The PET fibers melt during processing to furnish the matrix resin. About 14 layers are needed for a 100-mil molded thickness. Before transfer to the molding press, the stack is preheated in a convection oven for $30 \mathrm{~s}$ at about $300^{\circ} \mathrm{C}$ to melt the PET fibers and wet the glass reinforcement. In tests conducted thus

6 It is not known whether the weight reduction claimed by the developers includes structural supports. On the basis of information available in the open literature on similar technology, it is unlikely that net mass savings (including structure) exceeds $15 \%$. 
far, the heated XTC blanks are transferred manually from the oven to the press. In production, processors would probably employ robots.

The anticipated price is about twice that of SMC. However, based on an assumed weight saving of $15 \%$ and on manufacturing economies, DuPont figures indicate that the cost of an XTC vehicle hood would be about $\$ 2$ less than an SMC hood at volumes over 50,000 units per year. In contrast to SMC composites, the XTC composite is claimed to be easily and fully recyclable (Materials Engineering 1992).

Processing Aids. In the case of injection-moldable short-fiber thermoplastic composites, the necessity for uniformly dispersing and carrying chopped-glass fibers has engendered a demand for efficient processing aids. There is a need for glass-reinforced formulations that present a high melt flow index to allow the filling of large and complex molds, while keeping the mold temperature as low as possible to ensure short molding cycles. For automotive applications, the products should produce good surface finish to meet paintability requirements. High heat-distortion, impact, chemical, and environmental resistance are also required, in particular, for outside parts. The partly hydrogenated polyphenyls being developed by Monsanto seem to be an effective family of processing aids for glass-reinforced thermoplastics (Pierre 1992).

Mineral Fiber Reinforcement. About 10-15 years ago in the United States, considerable research and development work was being expended on thermoplastic composites containing dispersed mineral fibers as reinforcement (Katz and Milewski 1978). Typical of this work was DuPont's Fybex potassium titanate microfibers, with diameters of about 5 microns and lengths of about 100 microns. Thermoplastic/Fybex composites possessed an attractive combination of moldability, along with dimensional stability, stiffness, and high-quality surface finish. At one time, ALCOA (The Aluminum Company of America) was considering acicular sodium aluminum hydroxycarbonate (dawsonite) for a similar type of composite (Bonsignore 1976). Wollastonite, a naturally occurring calcium silicate mineral, is one microfiber-reinforcing agent that has been and is being used in large amounts in thermoplastic composites.

\subsubsection{Continuous-Fiber Composites for Structural Applications}

As discussed in Section 2, significant weight savings are possible, compared to steel, by using continuous-fiber PMCs in structural applications. For high-performance thermoplastic composites reinforced with continuous fibers, a comparison of properties among three different types of fibers is of interest (see Table 4). Compressive strength data is not available, but compressive strengths of these materials in woven formats embedded in a resin matrix are inherently low.

Companies involved in developing continuous-fiber thermoplastic composites include Thermoplastic Pultrusion, Inc. (Bartlesville, Okla.); Polymer Composites Inc., a division of Hoechst-Celanese Advanced Materials Group in the United States (Fiberod tapes, ribbons and 
TABLE 4 Material Property Comparison for Thermoplastic Fiber Composites ${ }^{a}$

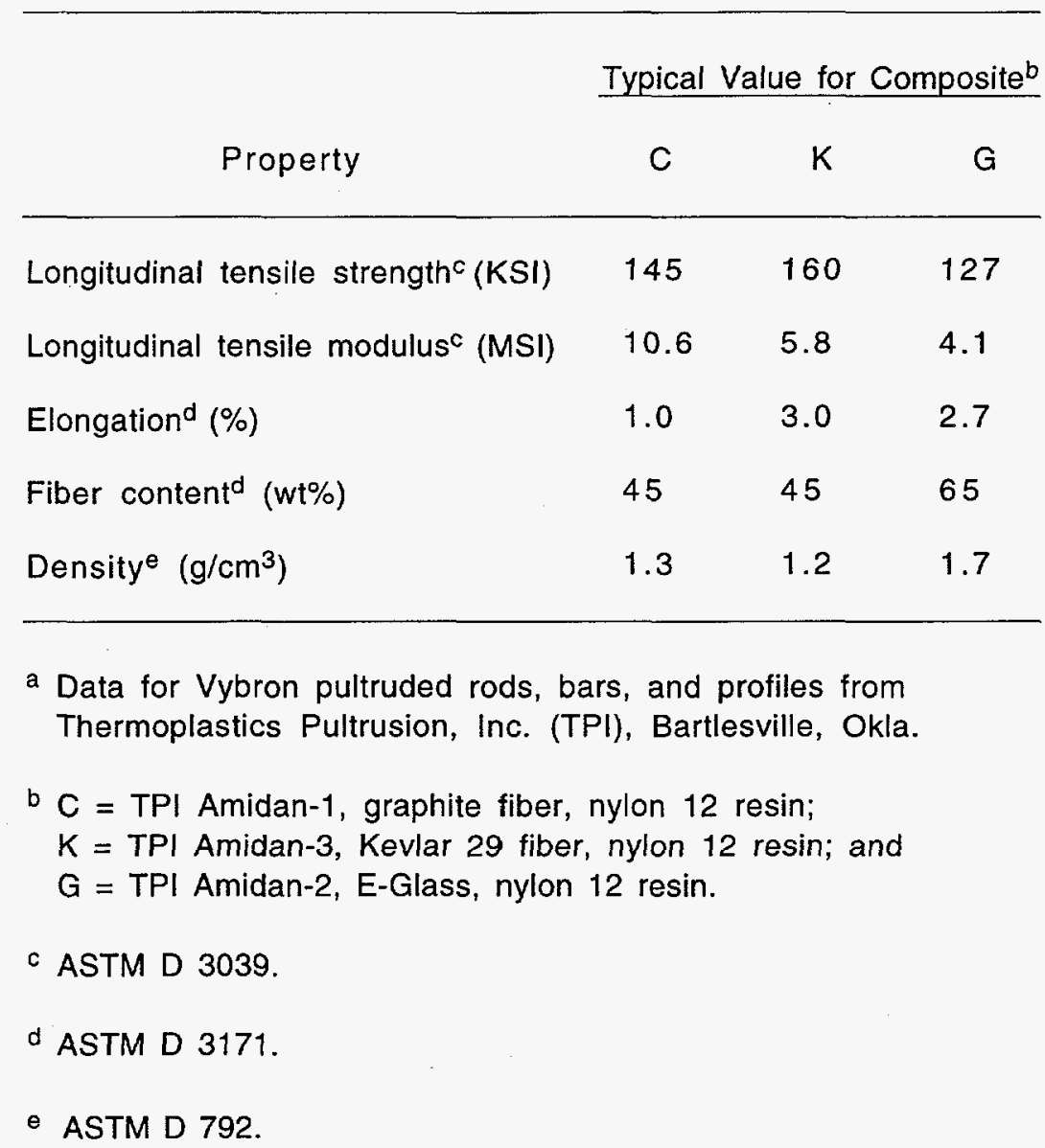

profiles); and Custom Composites, Inc., a start-up company spun off from Georgia Institute of Technology, Atlanta.

The adaptability of continuous-fiber reinforcements, containing an adhering shell of thermoplastic resin binder, to flat-shape exterior body panels is under serious study. A press release in the June 29,1992, issue of Chemical \& Engineering News (p. 9) noted:

DuPont and Hercules have, signed an agreement to jointly develop, manufacture, and market thermoplastic composites for aerospace and naval applications. . . . The two companies will focus on automated thermoplastic fiber placement technology in which resin-impregnated fibers are formed and fused simultaneously into a composite structure. The partnership grew out of a joint proposal developed ... by DuPont, Hercules, and the University of Delaware's Institute for Advanced Composites Technology; the proposal was awarded a $\$ 2.5$ million grant from the U.S. Defense Advanced Research Projects Agency for development of rapid manufacturing technologies. 


\subsection{Liquid Thermoplastic Composites (Cyclic Oligomer Polymerization)}

Adaptation of RTM technology to the formation of thermoplastic composite bodies could present significant processing advantages over thermoset RTM technology. ${ }^{7}$ General Electric (GE) has developed cyclic oligomer polymerization technology in which cyclic oligomers, consisting of rings of 2 to 20 repeating units, are subjected to the actions of an anionic catalyst. Ring opening polymerization occurs with formation of linear thermoplastic resins of molecular weight 50,000 to 700,000 .

Note that these cyclic oligomers are functionally related to the final polymer in that they are closed-ring analogs. Catalysts cause the breaking of a cyclic ring to form a new, open, and extended catalyst fragment that can continue to react sequentially with available cyclic oligomers to continue the polymer chain growth. Two especially important features of cyclic oligomer polymerization are that (1) the precursor monomer is much less volatile and hence less environmentally objectionable than the styrene monomer of conventional RTM thermoset resins and (2) the polymer matrix of the final cured composite is thermoplastic in nature and therefore should be more amenable to reclamation and recycling.

Several years ago, GE and Ford Motor Co. began a five-year, $\$ 10.8$ million joint venture to demonstrate production of structural composite auto parts. Cyclic oligomers, as low-viscosity liquids at $100^{\circ} \mathrm{C}$, readily wet and permeate glass reinforcement fibers, so that mold filling, cure, and demolding times should be significantly shorter than those for conventional thermoset RTM technology. The U.S. Department of Commerce contributed to the program along with GE and Ford.

\subsubsection{Liquid Crystal Polymers}

Resins. Liquid crystalline, wholly aromatic copolyesters are a class of thermoplastic polymers that exhibit a highly ordered structure in both the melt and solid states. These materials, referred to as liquid crystal polymers (LCPs), range from high-melting sinterable products to those that can be melt-processed on conventional molding equipment.

LCPs for injection molding provide significantly higher performance properties than other conventional polyesters, such as a heat distortion temperature under load (DTUL) of $350^{\circ} \mathrm{C}$ (264 psi). Two typical high-performance LCPs that are commercially available are the Xydar injection molding resins of Amoco Performance Products, Inc. (initially developed at Carborundum Corporation), and Vectra, first introduced by Celanese (now Ticona, a member of

7 For instance, as discussed in Section 3.2.3, by using the RTM process, the Dodge Viper body requires a fill, cure, and demold time of 6-15 min, thereby allowing a maximum production volume of only 3,000-5,000 units per year. Other major deficiencies of thermoset RTM technology include the release of objectionable styrene monomer vapors during processing and the fact that the final structural parts are completely thermoset and nonrecyclable. 
the Hoechst Group of the Hoescht Celanese Corporation ) (Huspeni et al. 1992). The chemical and physical properties of LCPs are discussed below.

Chemistry and Physical Properties. Xydar injection molding resins, which are based on terephthalic acid (TA); p, p', dihydroxy-biphenyl (DHB); and p-hydroxybenzoic acid (HBA), offer exceptional high-temperature strength, with DTULs of up to $340^{\circ} \mathrm{C}(264 \mathrm{psi})$. Vectra resin of Ticona can be characterized as primarily aromatic polyesters based on HBA and hydroxynaphthoic acid (HNA). Both types of polyesters consist of relatively rigid chains of long, flat, monomer units that are thought to undergo parallel ordering in the melt, forming tightly packed fibrous chains in molded parts. These polyesters are referred to as nematic, anisotropic, liquid crystalline, or self-reinforcing polymers (Huspeni et al. 1992). Table 5 gives a comprehensive catalog of the comparative physical properties of Xydar and Vectra, the two larger volume commercially available LCPs (see also Kwolek et al. 1990).

An ordered melt provides two immediate benefits. The low melt viscosity of these materials results in good injection-molding characteristics, comparable to those of such commodity resins as polypropylene, although at much higher temperatures. In addition, the densely packed, fibrous structure of molded parts provides exceptional physical properties. Unfortunately, these properties are highly direction-oriented and vary significantly between the flow and transverse directions.

Molded LCP resins display very high tensile and flexural properties at ambient and extreme temperatures. The room-temperature modulus of the Xydar high-heat materials is typically about 2.3 million psi, with some polymers maintaining a modulus of 600,000 psi at $300^{\circ} \mathrm{C}$. Tensile strengths range from about 20,000 to 30,000 psi, compressive strengths are considered low about $10,000 \mathrm{psi}$, and elongation is approximately $2 \%$, depending on filler level. Mechanical properties improve at subzero temperatures.

Other highly desirable properties of LCPs include outstanding thermal oxidative stability (for Xydar, a decomposition temperature of $560^{\circ} \mathrm{C}$ in air, with a UL rating as high as $260^{\circ} \mathrm{C}$ for continuous electrical service); excellent flame resistance (oxygen index of 42) and low smoke generation; excellent resistance to attack by virtually all chemicals; and the ability to withstand high levels of ultraviolet radiation. LCPs are available unfilled or filled with various combinations of mineral, glass, and carbon. In addition, glass-reinforced grades further extend the strength and heat characteristics. The addition of finely divided inert filler can lower the material's viscosity, while retaining a degree of self-reinforcement. This behavior is unlike that of conventional thermoplastics (Huspeni et al. 1992).

LCP Processing. LCPs can be injection molded into thin-wall components at high speeds with good replication of mold details. The high melt flow and fast setup permit the resin to be molded into large, heavy-wall parts as well. The thermal stability of the resin permits efficient use of regrind. 
TABLE 5 Properties of Xydar and Vectra Resins (both $30 \%$ glass-filled)

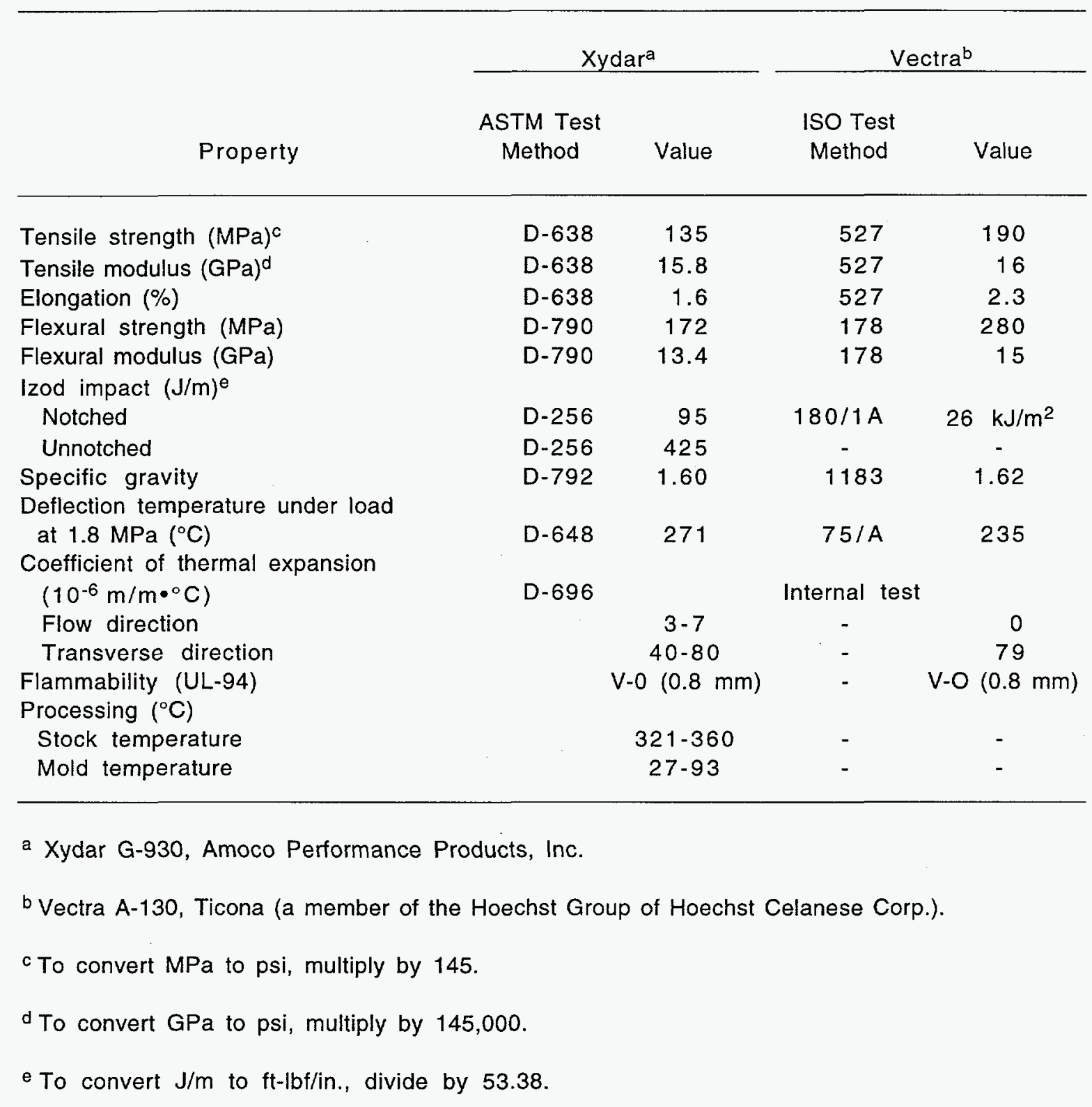

Conventional injection-molding machinery can be used. LCPs operate within barrel temperatures of $285-395^{\circ} \mathrm{C}$, depending on the grade. Injection pressures are in the range of 4,000-12,000 psi. Cycle times are as low as 5 seconds and are typically under 30 seconds. No post-curing is required. Current capacity of LCPs ranges from 4 million pounds annually for the naphthalene-based products to 22 million pounds for biphenol-based products. Prices range from approximately $\$ 7-\$ 10 / \mathrm{lb}$ in production quantities. Specialty grades may run higher, depending on the compound and quality.

The extended-rod configuration of LCPs can present significant mold design complications. Uncontrolled orientation effects in melt flow invariably result in irregular 
anisotropic physical property distributions for molded parts. Weld lines, where multiple flows of LCPs join, can be very weak and must be positioned to minimize such effects. The incorporation of fillers can improve the flow mixing of LCP streams with some homogenization of physical properties.

Compressive strengths for LCP polymers also tend to be unacceptably low, a natural concomitant of the long, slender, aligned microstructure of LCPs. In compression, the key factors are the torsional and bending rigidity of the molecule and the interactions between adjacent molecules (DeTeresa et al. 1985). The effect of the cross-sectional area in compression is opposite to the effect in tension. Molecules with large cross-sectional areas usually offer a higher potential for compressive strength. Consequently, a polymer molecule designed for optimal performance in tension will generally exhibit poor compressive strength and vice versa. Fillers and reinforcements can improve compressive strengths. An especially intriguing approach toward improved compressive strength for LCP composites is their use as reinforcing components of molecular composites in which a more traditional thermoplastic is used as the continuous matrix (see Section 5.2.2).

The cost of monomers and subsequent polymerization technology also remains a considerable drawback to the widespread and increasing acceptance of LCPs. The necessary aromatic phenols and dicarboxylic acid monomers are difficult to produce in high enough quantity and quality and at low enough cost.

\subsubsection{Blends of LCPs with Other Polymers (Molecular Composites)}

Blends and Composites. The intimate mixing of two or more polymers to form a new material with a unique property set has emerged as a desirable route to new product development. The resulting blend or alloy, if it consists of commercially available polymers, greatly reduces the time and costs associated with new materials development, while offering the possibility of a low-cost product with tailored properties and/or improved processibility.

Of particular interest for blends of LCPs with other thermoplastics is the possibility that the LCP phase becomes oriented during processing such that the matrix resin is reinforced. Such a system may be described as an "in-situ composite" or a "self-reinforcing polymer." "Molecular composite" is the term used to describe a molecular dispersion, ideally of rigid rod polymers (e.g., LCP in a conventional polymer matrix) (Samulski et al. 1990).

Molecular Composites. The concept of molecular composites has been evaluated by Flory in terms of a ternary system consisting of (1) the polymer rod (single macromolecule of the LCP type), (2) the conventional (random coil) polymer, and (3) the solvent. The evaluation predicts that a critical region will exist wherein there is a single isotropic phase consisting of rods randomly dispersed in the coils (Flory and Ronca 1979). This region is very narrow in its stability boundaries, and the retention of this structure in the solid state depends on "beating the kinetics." Hence, if phase separation can be avoided on solidification, the extraordinarily high mechanical 
properties of the individual macromolecular rods will result in products with excellent tensile and compressive properties (a significant fraction [one-third] of rods in such a solid is always in tension). If the composite material could be fabricated into three-dimensional parts, these parts would likely possess the high level of specific mechanical properties achievable with LCP-derived fibers.

Many of the reasons for blending LCPs with conventional polymers or with other LCPs are the same reasons that generally make blending an attractive polymer modification option. These reasons include cost reduction, property tailoring, accelerated new-product development, and improved processibility. The cost-reduction objective is to provide an LCP-like property set at appreciably less than "pure" LCP-property prices. Property tailoring is attractive from two points of view: (1) with conventional polymers, LCPs can function as high-modulus fibrous reinforcement, and (2) with other LCPs, or at relatively low levels of conventional polymer addition, the objective is to mitigate such LCP problems as poor weld line strengths or high anisotropy of properties. If a commercially useful family of LCP-containing resins can be defined, the rapid increase of new LCP-containing products will naturally follow. Improved processibility focuses on utilizing the low viscosity of the LCP to improve the processibility of highly viscous conventional resins. Finally, the blending of LCPs with other LCPs should provide useful data for studying the nature of the structure, morphology, and chain-to-chain interactions in these new LCP materials, while offering the opportunity of improved property sets (Samulski et al. 1990).

Such molecular composites are an active area of research as can be seen in a news release from Mazda Motor Corp. (Ashley 1992). In 1992, Mazda announced the development of a plastic composite that can lead to a greater and more effective use of recycled plastics. Mazda's new plastic composite combines easily recycled thermoplastics with LCPs for reinforcement. The LCPs are not destroyed during the recycling process because the polymer molecules rebond after melting. According to Mazda, the plastic can be recycled at least five times. 


\section{Conclusions}

What can be expected in the foreseeable future with regard to advanced PMC use in passenger cars? High performance composites were introduced in the early 1960s, and because of their very high initial cost, they found applications primarily within the aerospace industry. Later on, advanced PMCs found applications in high-value sporting goods and a few critical industrial components. As the volume of production of advanced reinforcing fiber increased, there were high expectations that the cost of the basic materials would decrease. However, this has not been the case. In fact, the trend has been almost in the opposite direction, with materials achieving higher performance at higher cost. Therefore, the role of advanced PMCs in the automotive industry for the foreseeable future appears to be limited to small, very critical components.

Expectations are higher for the use of fiberglass-based polymer composites. However, there are still significant limitations in the manufacturing process. The composites in volume use, such as SMCs, contain a relatively small amount of reinforcement material, which is by necessity short (in length of individual fibers) and randomly oriented. For the composite to yield high mechanical performance, it needs to have a high fiber content in a long, oriented fashion, which is difficult to do, especially at high volume and low labor cost. Even so, glass-fiber PMCs do not promise as much weight savings as aluminum.

For advanced PMCs (even fiberglass-based) to be used to a significant degree in automotive bodies or other material-intensive applications, it will be necessary to develop a process that is both productive (low in labor) and high in capacity. Right now, the only such process that appears feasible is the RTM process, which allows high fiber content yet maintains orientation. Large, relatively complex parts may be molded this way, but even this process is not particularly well-suited for large volumes. Due to the rather long cycle times, a typical production rate per machine is only on the order of a few thousand units per year. Adaptation of RTM to the formation of thermoplastic composite bodies could have a significant advantage over thermoset technology. Cyclic oligomers, which are precursors to thermoplastic matrix polymers, show promise for this application. Farther on the horizon are advanced composites compounded with the much more expensive (but stronger and stiffer) carbon-fiber reinforcement. However, significant price reductions of precursor materials and advances in processing and fabrication are needed. Although LCPs and LCP blends with other polymers (molecular composites) also hold promise, the cost of monomers and subsequent polymerization technology remains a considerable drawback to the widespread and increasing acceptance of LCPs.

Unless there are breakthroughs in polymer science and polymer materials processing, for the foreseeable future, lightweight vehicles will most likely be constructed primarily from light metals. Our findings suggest that not only should ways to produce low-cost carbon fibers be pursued, but also that a potentially more fruitful approach to ultralight vehicles would be to (1) develop new structural concepts for use of low-cost materials or minimize the use of expensive materials (such as sandwich structures), (2) adapt RTM to the formation of thermoplastic composite bodies using cyclic oligomers, (3) perform basic materials research to develop low-cost molecular composites that eliminate expensive preforms, and (4) perform basic materials research to lower the cost of monomers and subsequent polymerization technology. 


\section{References}

AAMA: see American Automobile Manufacturer's Association.

American Automobile Manufacturer's Association (formerly Motor Vehicle Manufacturers Association), various years [1987-1993], Motor Vehicle Facts and Figures, Detroit, Mich.

Applied Racing Technologies Group, 1993, "Price List," Mansfield, Texas, Aug.

Ashley, S., 1992, “GM's Ultralite Is Racing toward Greater Fuel Efficiency," Mechanical Engineering, pp. 64-67, May.

Bigg, D.M., and R.A. Markle, 1996, "Isocyanate Polymers for In-Mold Coating of Thermoplastic Sheet Composites," Plastics Engineering, pp. 31-34, Sept.

Bonsignore, P.V., 1976, “A New Flame Retardant Microfiber Reinforcement for Thermoplastics," Plastics Engineering, pp. 41-43, Oct.

Chang, D.C., W. Kuang-Ming, and J.R. Vella, 1981, Potential Mass Reduction and Material Cost Penalties of Body Panels with Alternate Materials, technical paper no. 810229, Society of Automotive Engineers, Inc., Warrendale, Penn.

Dale, G.H., 1980, "Hydrocarbons (Survey)," in Encyclopedia of Chemical Technology, Vol. 12, third edition, Kirk-Othmer (editor), John Wiley and Sons, New York, N.Y., pp. 870-892.

DeLong, D.J., 1994, "Carbon Fiber Economics/Applications," prepared for the Gorham/Intertech Conference, July 21.

DeLong, D.J., 1995, personal communication, Amoco Performance Products, Inc., Feb. 23.

DeTeresa, S.J., R.S. Porter, and R.J. Farris, 1985, "A Model for the Compressive Buckling of Extended Chain Polymers,” Journal of Material Science 20(5):1645-1659.

Dieffenbach, J.R., 1992, "Life-Cycle Savings Make Strong Case for Plastics," Plastics World, pp. 50-53.

Economy, J., 1995, University of Illinois, personal communication, Jan. 6. 
Flory, P.J., and G. Ronca, 1979, "Theory of Systems of Rod-Like Particles. 2. Thermotropic Systems with Orientation-Dependent Interactions," Molecular Crystals and Liquid Crystals, 155:129-139.

High-Performance Composites Sourcebook '96, 1995, Ray Publishing, Inc., Wheat Ridge, Colo.

Hull, J.L., 1990, "Compression and Transfer Molding," in Concise Encyclopedia of Polymer Science and Engineering, J.I. Kroschwitz (editor), John Wiley and Sons, Inc., New York, N.Y., pp. 186-189.

Huspeni, P.J., et al., 1992, "Liquid Crystal Polymers," in Modern Plastics Encyclopedia '92, McGraw-Hill, New York, N.Y., pp. 1-42, Oct.

Katz, H.S., and J.V. Milewski, 1978, "Short Fiber Reinforcements," Section X in Handbook of Fillers and Reinforcements for Plastics, H.S. Katz and J.V. Milewski (editors), Van Nostrand Reinhold Company, New York, N.Y., pp. 405-484.

Kruder, G.A., 1990, "Extrusion," in Concise Encyclopedia of Polymer Science and Engineering, J.I. Kroschwitz (editor), John Wiley and Sons, Inc., New York, N.Y., pp. 363-367.

Kwolek, S.L., P.W. Morgan, and J.R. Schaefgen, 1990, "Liquid Crystalline Polymers," in Concise Encyclopedia of Polymer Science and Engineering, J.I. Kroschwitz (editor), John Wiley and Sons, Inc., New York, N.Y., pp. 547-555.

Lin, S-S., 1992, "Recent Developments of Carbon Fiber in Japan," SAMPE (Society for the Advancement of Material and Process Engineering) Journal, 28(4):9-19, July/Aug.

Mao, T.J., 1990, "Sheet Molding Compounds," in Concise Encyclopedia of Polymer Science and Engineering, J.I. Kroschwitz (editor), John Wiley and Sons, Inc., New York, N.Y., pp. $1044-1045$.

Materials Engineering, 1992, "Thermoplastic Composite for Horizontal Body Panels," pp. 3,12, April.

Miller, B., 1992, "Plastics Lighten the Ride in the 93's," Plastics World, p. 42, Oct.

Pierre, J., 1992, "Polyphenyl Processing Aids for Glass Reinforced Polymers and Alloys," Automotive Polymers and Design, pp. 13-17, Feb.

Plastics World, 1992, "Viper is a Fast Track Design by Necessity," pp. 28-29, April. 
Reinhart, T.J., and L.L. Clements, 1987, "Introduction to Composites," Engineered Materials Handbook, Vol. 1, ASM International, Metals Park, Ohio, pp. 27-34.

Robinson, M.J., 1991, A Qualitative Analysis of Some of the Issues Affecting the Cost of Composites Structures, American Society of Mechanical Engineers, New York, N.Y.

Rubin, I.I., 1990, "Injection Molding," in Concise Encyclopedia of Polymer Science and Engineering, J.I. Kroschwitz (editor), John Wiley and Sons, Inc., New York, N.Y., pp. 469-472.

Samulski, E.T., et al., 1990, "Molecular Composites," in Liquid Crystalline Polymers, report NMAB-453, National Materials Advisory Board, E.T. Samulski, chairman, National Academy Press, p. 37.

Schwartz, M.M., 1984, Composite Materials Handbook, McGraw-Hill, Inc., New York, N.Y., pp. 2.42-2.52.

Sherman, A.M., 1995, "Future Research for Aluminum Vehicle Structure," remarks at U.S. Department of Energy/National Science Foundation Conference on Basic Research Needs for Vehicles of the Future, New Orleans, La., Jan. 5.

Slobodzinsky, A., 1982, "Bag Molding Processes," Chapter 14 in Handbook of Composites, G. Lubin (editor), Society of Plastics Engineers, Van Nostrand Reinhold Company, New York, N.Y.

Society of the Plastics Industry, 1992, "1992 Model Year Passenger Car and Truck SMC Components," SMC Automotive Alliance, SPI Composites Institute, New York, N.Y.

Society of the Plastics Industry, 1997, SPI Committee on Resin Statistics, as compiled by Association Services Group, LLC.

SPI: see Society of the Plastics Industry.

Tibbetts, G.G., 1990, "Carbon Fibers from Vapor Phase Hydrocarbons," technical paper no. 901036, Society of Automotive Engineers, Inc., Warrendale, Penn.

University of Michigan, 1994, Delphi VII Forecast and Analysis of the U.S. Automotive Industry, Volume 3: Materials, Office for the Study of Automotive Transportation, University of Michigan, Ann Arbor, Mich., Feb. 
U.S. Congress, 1988, Advanced Materials by Design, report PB88-243548, Office of Technology Assessment, Washington, D.C., June.

Ward's Automotive Yearbook, various years [1973-1990], Ward's Communications, Inc., Detroit, Mich.

Winter, D., 1994, “RTM Eyed for 'Supercar'," Ward's Auto World, July. 


\section{Bibliography}

1. Concise Encyclopedia of Polymer Science and Engineering, 1990, J.I. Kroschwitz (editor), John Wiley and Sons, Inc., New York, N.Y.

2. Handbook of Composites, 1982, G. Lubin (editor), Society of Plastics Engineers, Van Nostrand Reinhold Company, New York, N.Y.

3. Handbook of Fillers and Reinforcements for Plastics, 1978, H.S. Katz and J.V. Milewski (editors), Van Nostrand Reinhold Company, New York, N.Y.

4. Liquid Crystalline Polymers, 1990, National Materials Advisory Board, E.T. Samulski, chairman, report NMAB-453, National Academy Press.

5. Advanced Materials: Outlook and Information Requirements, 1989, Proceedings, Bureau of Mines Conference, November 7-8, 1989, Information Circular 9274, U.S. Bureau of Mines. 